\title{
Financial Incentives and Diabetes Disease Control in Employees: A Retrospective Cohort Analysis
}

\author{
Anita D. Misra-Hebert, MD, MPH ${ }^{7}, \mathrm{Bo} H u, \mathrm{PhD}^{2}$, Glen Taksler, $\mathrm{PhD}^{7}$, Robert Zimmerman, $\mathrm{MD}^{3}$, and \\ Michael B. Rothberg, $M D, M P H^{1}$
}

${ }^{1}$ Center for Value-Based Care Research, Medicine Institute, Cleveland Clinic, Cleveland, OH, USA; ${ }^{2}$ Department of Quantitative Health Sciences, Cleveland Clinic, Cleveland, OH, USA; ${ }^{3}$ Diabetes Center, Endocrinology and Metabolism Institute, Cleveland Clinic, Cleveland, OH, USA.

BACKGROUND: Many employers offer worksite wellness programs, including financial incentives to achieve goals. Evidence supporting such programs is sparse.

OBJECTIVE: To assess whether diabetes and cardiovascular risk factor control in employees improved with financial incentives for participation in disease management and for attaining goals.

DESIGN: Retrospective cohort study using insurance claims linked with electronic medical record data from January 2008-December 2012.

PARTICIPANTS: Employee patients with diabetes covered by the organization's self-funded insurance and propensity-matched non-employee patient comparison group with diabetes and commercial insurance.

INTERVENTION: Financial incentives for employersponsored disease management program participation and achieving goals.

MAIN MEASURES: Change in glycosylated hemoglobin (HbA1c), low-density lipoprotein (LDL), systolic blood pressure (SBP), and weight.

RESULTS: A total of 1092 employees with diabetes were matched to non-employee patients. With increasing incentives, employee program participation increased $(7 \%$ in 2009 to $50 \%$ in 2012, p < 0.001). Longitudinal mixed modeling demonstrated improved diabetes and cardiovascular risk factor control in employees vs. non-employees [HbAlc yearly change -0.05 employees vs. 0.00 non-employees, difference in change (DIC) $\mathrm{p}<0.001$ ]. In their first participation year, employees had larger declines in $\mathrm{HbAlc}$ and weight vs. non-employees (0.33 vs. 0.14 , DIC $\mathrm{p}=0.04)$ and (2.3 kg vs. $0.1 \mathrm{~kg}$, DIC p<0.001), respectively. Analysis of employee cohorts corresponding with incentive offerings showed that fixed incentives (years 1 and 2) or incentives tied to goals (years 3 and 4) were not significantly associated with $\mathrm{HbAlc}$ reductions compared to non-employees. For each employee cohort offered incentives, SBP and LDL also did not significantly differ in employees compared with non-employees (DIC p >0.05).

CONCLUSIONS: Financial incentives were associated with employee participation in disease management and improved cardiovascular risk factors over 5 years.

Electronic supplementary material The online version of this article (doi:10.1007/s11606-016-3686-2) contains supplementary material, which is available to authorized users.

Received July 2, 2015

Revised December 15, 2015

Accepted March 16, 2016

Published online April 11, 2016
Improvements occurred primarily in the first year of participation. The relative impact of specific incentives could not be discerned.

KEY WORDS: diabetes; chronic disease; disease management; health promotion.

J Gen Intern Med 31(8):871-7

DOI: $10.1007 / \mathrm{s} 11606-016-3686-2$

(C) Society of General Internal Medicine 2016

\section{INTRODUCTION}

The prevalence of diabetes in the US continues to rise as obesity prevalence increases. ${ }^{1}$ While factors affecting optimal self-care behaviors such as stable psychosocial resources ${ }^{2}$ or having health insurance $^{3}$ contribute to glycemic control, diabetes control is also affected by lifestyle choices. ${ }^{4}$ Three-quarters of the disabilityadjusted life years attributable to diabetes are related to bodymass index (BMI), ${ }^{5}$ a modifiable lifestyle risk factor. Medical expenses for persons with diabetes are estimated to be 2.5 times higher than for those without diabetes, ${ }^{6}$ with an estimated cost of 245 billion dollars in 2012 including direct medical costs and reduced productivity. ${ }^{7}$

Worksite wellness programs may improve diabetes control through encouraging lifestyle changes and disease management. Healthy changes in the work environment may impact employees, whether or not they participate in disease management programs. ${ }^{8}$ Financial incentives may promote health behavior change. ${ }^{9}$ Incentives tied to wellness program participation have been shown to affect health behaviors such as smoking ${ }^{10-12}$ and reduce downstream health care costs. ${ }^{13}$ Incentives for achieving specific health goals, such as a target glycosylated hemoglobin (HbA1c) or blood pressure, remain uncommon ${ }^{14}$ and have not been well studied.

One obstacle to understanding the effectiveness of financial incentives in chronic disease management is the lack of randomized trials. Observational studies comparing voluntary participants in workplace wellness programs to non-participants are subject to selection bias because highly motivated employees may be more likely to participate and thus may differ from non-participants. In contrast, a research design that considers disease control among all employees exposed to incentives (not just those who accept) compared with disease control among 
similar non-employees obtaining regular care can control for this type of bias.

The purpose of this study was to assess the impact of financial incentives on control of diabetes and other cardiovascular risk factors in employees. We hypothesized that compared with non-employees obtaining regular care at the same primary care practices, employees offered financial incentives would show greater improvements in diabetes and cardiovascular risk factor control. We also hypothesized that employees who participated in disease management programs would have greater improvements than those who did not.

\section{METHODS}

The Cleveland Clinic employee health program (EHP) is a selffunded insurance plan covering $>38,000$ employees. We conducted a retrospective cohort study using EHP claims data linked with electronic medical record (EMR) data from January 2008December 2012. The study was approved by the Institutional Review Board at Cleveland Clinic. Participants included EHP members with diabetes. The comparison group included patients with diabetes with commercial health insurance cared for by the

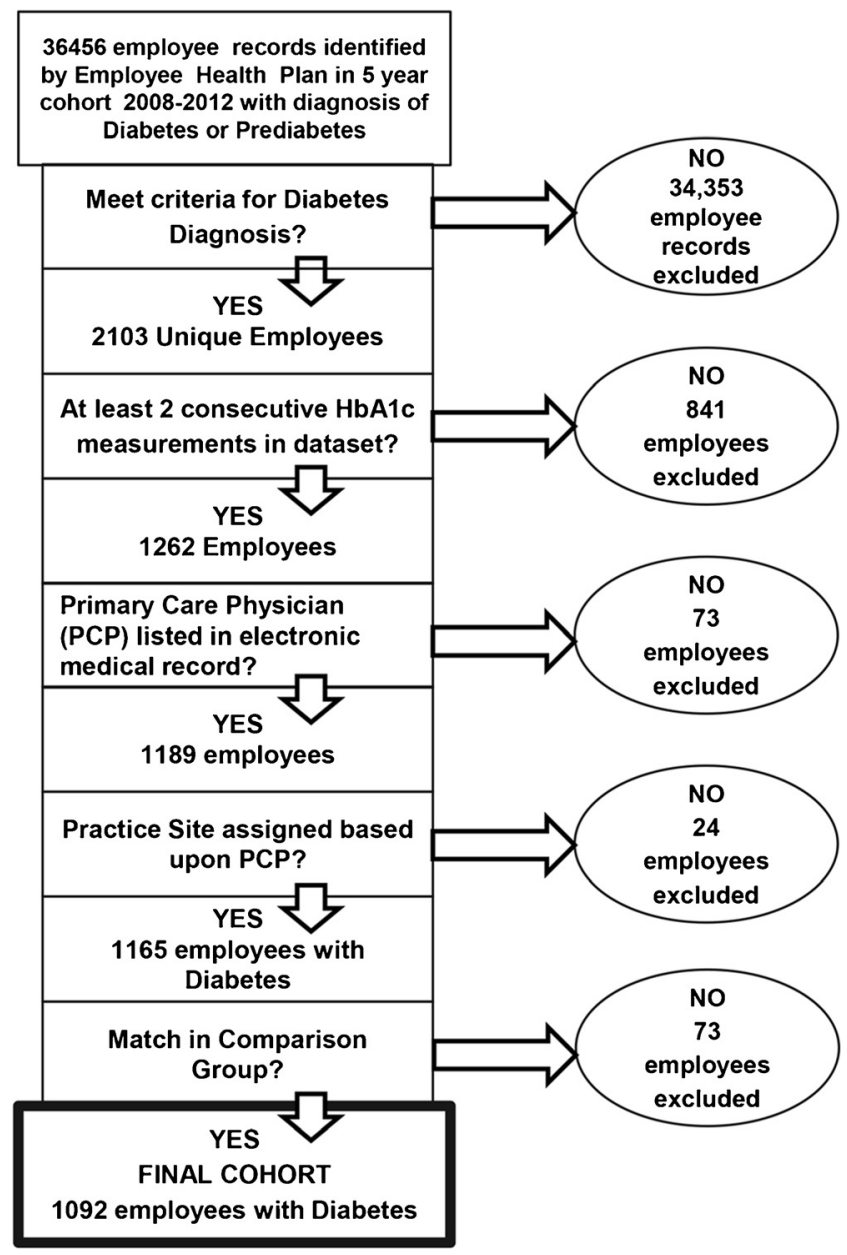

Figure 1 Employee diabetes cohort. same group of primary care physicians during the study period. Our employee study cohort was created as outlined in Figure 1. Applying the standard Healthcare Effectiveness Data and Information Set (HEDIS) definition, we used claims data to identify employees with diabetes. Employee claims were then linked to the EMR. To confirm a diabetes diagnosis, we excluded any employee without either (1) an HbA1c $>6.5 \%$ on the first value in the dataset or (2) two International Classification of Diseases, Ninth Revision (ICD 9) codes for diabetes and a diabetes medication prescribed. To analyze the impact of the overall incentive program, we performed a longitudinal analysis including all employees who had $\mathrm{HbA} 1 \mathrm{C}$ measures in at least 2, not necessarily consecutive, years during the study period. To analyze the effect of specific incentives, we created 2-year cohorts (2008-09, 2009-10, 2010-11, 2011-12). For each cohort, the first year represented the baseline and the second year corresponded with the introduction of a financial incentive; any employee who did not have at least one $\mathrm{HbAlc}$ measurement in each of the 2 study years was excluded from that cohort. The average HbAlc for employees excluded at this step was 7.03 [standard deviation (SD) 1.81] vs. 7.43 (SD 1.75) for included employees. We then excluded employees who did not have a primary care physician (PCP) in the EMR - indicating they did not obtain their routine care in our health system. Based upon the PCP, a primary practice site was assigned. Using EHP records, we designated each employee as participating or not participating in disease management programs in each year. For employee participants in disease management, we created a pooled cohort from all four 2-year cohorts to allow analysis of outcomes of employees in their first year of program participation.

\section{Exposures}

Exposures include the programs offered to all employees. Beginning in July 2005, the Cleveland Clinic implemented a series of wellness initiatives, initially focused on changing the work environment to promote healthier lifestyles. Starting in 2008, the EHP offered free smoking cessation, weight management, and fitness programs.

The EHP also administers disease management programs for diabetes and other cardiovascular risk factors including obesity, hypertension, and hyperlipidemia. In 2009, a fixed \$100 financial incentive was offered for participation in an employer-sponsored disease management program; the incentive increased to $\$ 300$ in 2010. In 2011, the incentive changed to a $30 \%$ health insurance premium discount (\$600-\$1200 depending on type of plan) tied to both participation (15\% discount) and achievement of clinical goals (additional $15 \%$ discount). The same incentive continued in 2012. Clinical goals included achievement of set HbA1c, lowdensity lipoprotein (LDL) cholesterol, and blood pressure targets. If requested, the $\mathrm{HbA} 1 \mathrm{c}$ target could be individualized, but $>90 \%$ of employees had a standardized goal of $<7 \%$. Target for LDL was $<100 \mathrm{mg} / \mathrm{dl}$ and for systolic blood pressure (SBP) $<130$. The weight target was individualized. Premium discounts were applied in the year following participation or achievement of goals. 


\section{Outcome Measures}

Our primary outcome measure was absolute change in HbA1c. Secondary outcomes included change in LDL, SBP, and weight.

\section{Statistical Analysis}

Each employee was matched to a non-employee in a 1-to-1 ratio based on propensity scores. The logistic models for calculating propensity scores included $\mathrm{HbAlc}$, age, gender, race, BMI, insulin use and practice site at the matching (baseline) year as covariates. Matching variables were chosen based upon (1) diabetes control and disease burden (HbAlc, insulin use), (2) demographic and clinical factors that may affect diabetes control or prescribed targets (age, ${ }^{15,16}$ gender, ${ }^{17}$ race, ${ }^{18} \mathrm{BMI}$ ), and (3) care delivered by the same group of providers(practice site).

Our data were analyzed in three ways: (1) longitudinal mixed modeling of outcomes for the 5 year cohort (200812 ) of employees and matched non-employees, (2) analysis of matched 2-year cohorts of employees (2008-09, 2009-10, 2010-11, 2011-12) and non-employees to assess the impact of individual incentives, and (3) pooled analyses of outcomes of all employee disease management program participants in their first year of program participation compared to matched non-employees.

First, to assess 5-year outcomes of employees compared to non-employees, a longitudinal linear mixed model was created using the data for all employees and non-employees in the dataset. Second, to assess the impact of each separate incentive offering, we analyzed the data in 2-year cohorts to correspond with timing of incentives. Employees were divided into four cohorts according to the years of their first $\mathrm{HbAlc}$ measurement (i.e., 2008, 2009, 2010, and 2011). Within each cohort, all employees who had a propensity score (no missing baseline BMI) were matched. While an employee could be included in more than one cohort, the employee was matched to a different non-employee in each cohort. Propensity score subclassifications and outcomes of matched employees and non-employee comparison group by quartiles are shown in Appendix Figs. S1-S4 and Tables S1-S4, respectively. We used the Rpackage (Matching) to perform the propensity matching. ${ }^{19}$

Baseline characteristics of the matched employees and comparison group were compared using the t-test and chi-squared test for continuous and categorical characteristics, respectively. For each cohort, we compared the outcome in the matching year and the year after using the paired t-test for matched employees and comparison group, respectively, and compared the 1-year changes between the employees and comparison group using the t-test.

Third, to analyze the effect of disease management program participation, for employees who participated in diabetes and weight management programs at any time between 2008 2012 (in any of the cohorts), we used a pooled analysis to compare the baseline(year prior to program participation)
HbAlc and weight for an employee to the outcomes for the same group of employees in the first year of program participation; we then assessed the outcome changes in the same time period for the matched comparison group.

Statistical significance was considered at $p$-values less than 0.05 . Results were not adjusted for multiple comparisons. All analyses were conducted using SAS 9.3 (Cary, NC) and Rstudio (Boston, MA).

\section{RESULTS}

There were 1092 employees matched to non-employees. Characteristics of the study population appear in Table 1 . Comparison of matched vs. unmatched employees appears in Appendix Table S5.

The proportion of all eligible employees enrolled in the programs increased from $7 \%(\mathrm{n}=52 / 793)$ in 2009 to $50 \%$ $(\mathrm{n}=498 / 1004)$ in $2012(\mathrm{p}<0.001)$ with employees entering and leaving the program during this time (Appendix Fig. S5). However, for employees with poorly controlled diabetes (baseline HbA1c>9), $9.8 \%(n=8 / 82)$ enrolled in 2009 and increased to only $39.3 \%(n=48 / 122)$ in 2012 . Thus, the baseline mean $\mathrm{HbAlc}$ of participants joining the program fell from 7.52 in 2009 to 7.35 in 2012.

Over 5 years, at the population level, employees had greater reductions in $\mathrm{HbA1c}$, SBP, LDL, and weight than did the nonemployee comparison group (Table 2). Additional sensitivity analyses modeling the longitudinal changes in outcomes based upon when employees entered the cohorts appear in Appendix Table S6. Employees had greater weight loss than the comparison group whenever they entered but more significant lowering of $\mathrm{HbAlc}$ than the comparison group only when entering in 2008 and 2010.

At the population level, fixed, small financial incentives (2008-09 and 2009-10 cohorts) and the first year in which incentives were tied to treatment targets (2010-11 cohort) were not associated with a significant decreases of $\mathrm{HbAlc}$ among employees (Table 3 ). In the second year that incentives were tied to treatment targets (2011-12 cohort), HbA1c declined significantly among employees and the comparison group, with no significant difference between the two groups. Weight decreased in employees throughout the study period, with significant changes compared to the non-employees only in the initial cohort. Changes in mean LDL and SBP throughout the study period were similar for the employees and comparison group (difference in change $p>0.05$ for all cohorts). Sensitivity analyses applying linear mixed models to the 2-year cohorts revealed similar results (Appendix Table S7).

Subgroup analyses for patients with $\mathrm{HbA1c}>9$ or $\mathrm{BMI}>27$ (Appendix Table S8) showed a significant and similar decreases in HbAlc in employees and the non-employee comparison group. Weight also decreased similarly for both groups except in the last cohort - the second year in which 
Table 1 Baseline Characteristics of Matched Employee and NonEmployee Cohorts

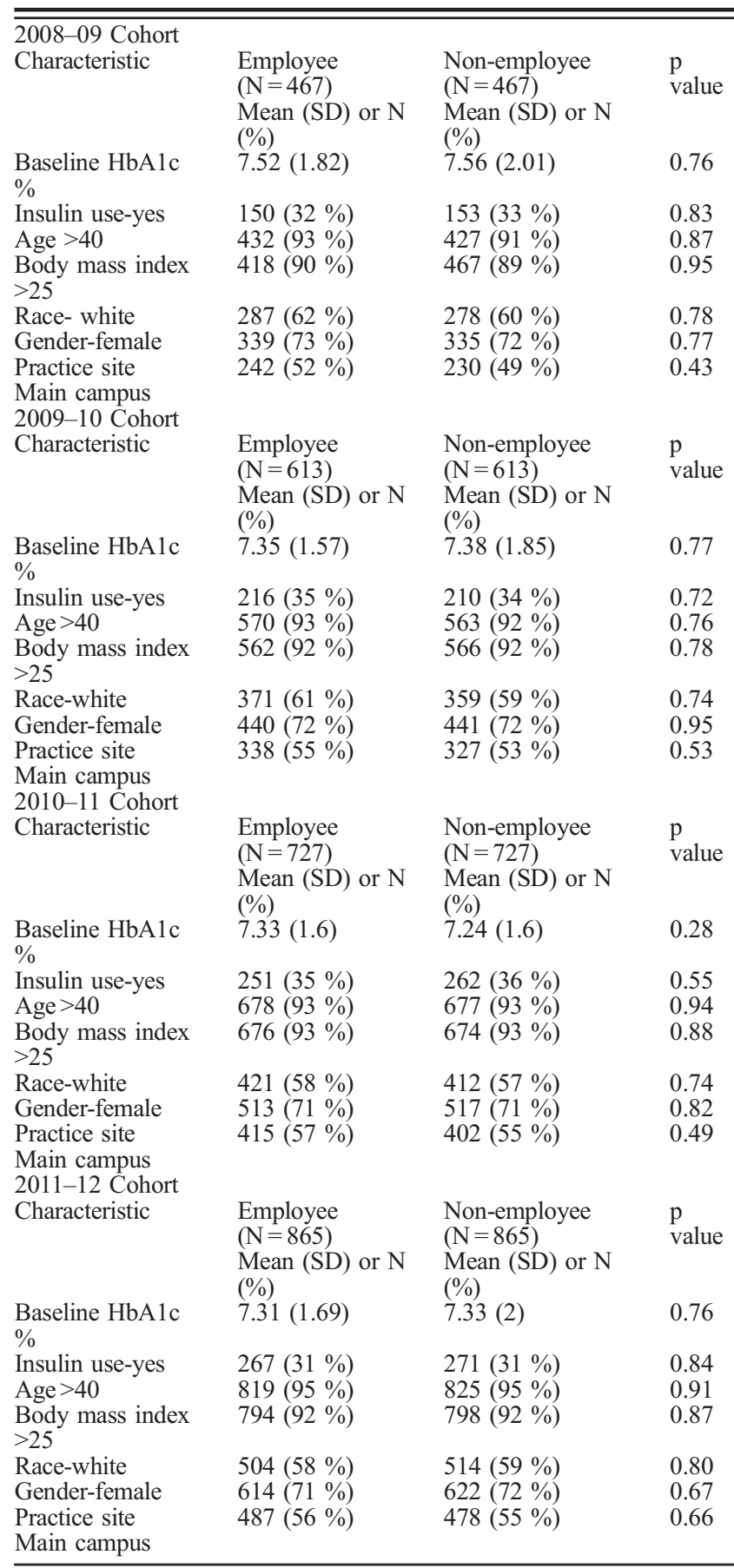

$S D=$ standard deviation

incentives were tied to treatment targets-when employees' weight decreased significantly more.

For employees participating in disease management programs, a pooled analysis demonstrated that in their first year in the program, their $\mathrm{HbAlc}$ declined by an average of 0.33 points $(\mathrm{p}<0.001)$ and weight by $2.3 \mathrm{~kg}(\mathrm{p}<0.001)$ (Table 4$)$, greater than noted in the non-employee comparison group.

To further assess outcomes of program participants vs. nonparticipants, we analyzed changes in $\mathrm{HbAlc}$ and weight for "ever-participants" in 2008-12 as compared to "always non-
Table 2 Longitudinal Mixed Model of Yearly Changes of Outcomes between Matched Employees and Non-Employee Comparison Group 2008-2012 (Includes All Data)

\begin{tabular}{|c|c|c|c|c|c|}
\hline & \multicolumn{2}{|c|}{$\begin{array}{l}\text { Employee } \\
(\mathrm{N}=\mathbf{2 1 0 3})\end{array}$} & \multicolumn{2}{|c|}{$\begin{array}{l}\text { Non-employee } \\
\text { comparison } \\
\text { group }(N=2672)\end{array}$} & \multirow[t]{2}{*}{$\begin{array}{l}\text { for } \\
\text { difference } \\
\text { in change }\end{array}$} \\
\hline & $\begin{array}{l}\text { Mean } \\
\text { (SE) }\end{array}$ & $\mathbf{p}$ & $\begin{array}{l}\text { Mean } \\
\text { (SE) }\end{array}$ & p & \\
\hline $\mathrm{HbA1c} \%$ & $\begin{array}{l}-0.05 \\
(0.01)\end{array}$ & $<0.001$ & $\begin{array}{l}0.00 \\
(0.01)\end{array}$ & 0.88 & $<0.001$ \\
\hline $\mathrm{SBP}(\mathrm{mmHg})$ & $\begin{array}{l}-0.01 \\
(0.13)\end{array}$ & 0.94 & $\begin{array}{l}0.30 \\
(0.08)\end{array}$ & $<0.001$ & 0.03 \\
\hline LDL(mg/dl) & $\begin{array}{l}-3.20 \\
(0.30)\end{array}$ & $<0.001$ & $\begin{array}{l}-2.35 \\
(0.18)\end{array}$ & $<0.001$ & 0.01 \\
\hline Weight (kg) & $\begin{array}{l}-0.73 \\
(0.07)\end{array}$ & $<0.001$ & $\begin{array}{l}-0.37 \\
(0.05)\end{array}$ & $<0.001$ & $<0.001$ \\
\hline
\end{tabular}

$S E=$ Standard error

$S B P=$ Systolic blood pressure

$L D L=$ Low density lipoprotein

participants." Weight decreased significantly more in employees who participated in disease management at any time compared to non-participants (yearly change $-1.07 \mathrm{~kg}$ vs. $0.39 \mathrm{~kg}, \mathrm{p}<0.001)$ but HbAlc did not $(-0.06 \%$ vs. $-0.04 \%$, p 0.39, Appendix Table S9).

\section{DISCUSSION}

In this retrospective study of employees with diabetes in a single institution, the implementation of financial incentives to join disease management programs was associated with an increase in program participation. As the initial goal of the financial incentives was to encourage employees with diabetes to join disease management, this program succeeded. Our longitudinal modeling suggests that on a population level the offering of incentives coupled with disease management improved diabetes and cardiovascular risk factor control in employees compared to matched non-employees. However, our analysis of 2-year cohorts corresponding to the timing of increasing incentives and incentives for attaining treatment goals did not demonstrate a temporal association between individual incentives and improvements in any study outcomes for employees versus the comparison group. Even employees with an $\mathrm{HbAlc}>9$, who showed substantial improvement in $\mathrm{HbAlc}$ in all cohorts, had changes similar to those seen in non-employees (Appendix Table S8).

Our ability to demonstrate population benefits over the full 5 years, but inability to attribute those benefits to the implementation of particular incentives, may be an artifact of the study design. We found that among employees already in care, i.e., those who had an $\mathrm{HbAlc}$ measure in consecutive years, and included in the 2-year cohorts, the incentives did not appear to have any impact when compared to nonemployees also obtaining regular care. For those who may have sought care and improved their measures within the same year, their improvements would have been missed by the cohort analysis, but measured in the longitudinal analysis. 
Table 3 Outcomes of Employee Patients with Diabetes and Matched Non-Employee Comparison Group: 2-year Cohorts

\begin{tabular}{|c|c|c|c|c|c|c|c|}
\hline \multirow[t]{2}{*}{ Outcome } & \multirow[t]{2}{*}{ Cohort (\$ incentive) } & \multirow[t]{2}{*}{ Group } & \multirow[t]{2}{*}{$\mathbf{N}$} & \multirow{2}{*}{$\frac{\text { Year } 1}{\text { Mean(SD) }}$} & \multirow{2}{*}{$\begin{array}{l}\text { Change year } \\
2 \text {-year } 1 \\
\text { estimate }\end{array}$} & \multirow{2}{*}{$\begin{array}{l}\text { p value year } \\
2 \text {-year } 1 \\
\text { change }\end{array}$} & \multirow{2}{*}{$\begin{array}{l}p \text { value } C-E \\
\text { difference in } \\
\text { change }\end{array}$} \\
\hline & & & & & & & \\
\hline \multirow[t]{8}{*}{ HbA1c $(\%)$} & \multirow[t]{2}{*}{$2008-2009(\$ 100)$} & $\mathrm{E}$ & 467 & $7.52(1.82)$ & -0.13 & 0.06 & \multirow[t]{2}{*}{0.92} \\
\hline & & $\mathrm{C}$ & 467 & $7.56(2.01)$ & -0.14 & 0.04 & \\
\hline & \multirow[t]{2}{*}{ 2009-2010(\$300) } & $\mathrm{E}$ & 613 & $7.35(1.57)$ & -0.07 & 0.18 & \multirow[t]{2}{*}{0.41} \\
\hline & & $\mathrm{C}$ & 613 & $7.38(1.85)$ & -0.14 & 0.01 & \\
\hline & 2010 & $\mathrm{E}$ & 727 & $7.33(1.60)$ & -0.08 & 0.08 & \multirow[t]{2}{*}{0.62} \\
\hline & $2011(\$ 600-\$ 1200)$ & $\mathrm{C}$ & 727 & $7.24(1.64)$ & -0.05 & 0.25 & \\
\hline & $2011-$ & $\mathrm{E}$ & 865 & $7.31(1.69)$ & -0.18 & $<0.001$ & \multirow[t]{2}{*}{0.20} \\
\hline & $2012(\$ 600-\$ 1200)$ & $\mathrm{C}$ & 865 & $7.33(2.00)$ & -0.26 & $<.0 .001$ & \\
\hline \multirow{8}{*}{$\begin{array}{l}\text { Systolic blood } \\
\text { pressure(mmHg) }\end{array}$} & \multirow[t]{2}{*}{$2008-2009(\$ 100)$} & $\mathrm{E}$ & 461 & $127.8(14.4)$ & -0.5 & 0.45 & \multirow[t]{2}{*}{0.34} \\
\hline & & $\mathrm{C}$ & 466 & $126.8(13.7)$ & 0.4 & 0.56 & \\
\hline & \multirow[t]{2}{*}{$2009-2010(\$ 300)$} & $\mathrm{E}$ & 607 & $127.9(14.0)$ & -0.1 & 0.90 & \multirow[t]{2}{*}{0.58} \\
\hline & & $\mathrm{C}$ & 610 & $128.6(14.0)$ & -0.5 & 0.35 & \\
\hline & 2010 & $\mathrm{E}$ & 721 & $128.6(13.7)$ & -0.3 & 0.49 & \multirow[t]{2}{*}{0.94} \\
\hline & $2011(\$ 600-\$ 1200)$ & $\mathrm{C}$ & 724 & $128.4(14.5)$ & -0.4 & 0.45 & \\
\hline & $2011-$ & $\mathrm{E}$ & 860 & $128.9(14.0)$ & -0.7 & 0.08 & \multirow[t]{2}{*}{0.89} \\
\hline & $2012(\$ 600-\$ 1200)$ & $\mathrm{C}$ & 862 & $129.0(14.3)$ & -0.7 & 0.14 & \\
\hline \multirow[t]{8}{*}{ LDL cholesterol(mg/dl) } & $2008-2009(\$ 100)$ & $\mathrm{E}$ & 360 & $103.6(32.0)$ & -5.8 & $<0.001$ & \multirow[t]{2}{*}{0.35} \\
\hline & & $\mathrm{C}$ & 366 & $103.1(33.2)$ & -3.7 & 0.02 & \\
\hline & \multirow[t]{2}{*}{ 2009-2010(\$300) } & $\mathrm{E}$ & 474 & $100.6(32.3)$ & -6.7 & $<0.001$ & \multirow[t]{2}{*}{0.06} \\
\hline & & $\mathrm{C}$ & 458 & $101.9(31.4)$ & -1.7 & 0.18 & \\
\hline & 2010 & $\mathrm{E}$ & 563 & $97.5(30.5)$ & -3.1 & 0.01 & \multirow[t]{2}{*}{0.92} \\
\hline & $2011(\$ 600-\$ 1200)$ & $\mathrm{C}$ & 543 & $100.6(31.4)$ & -3.2 & $<0.01$ & \\
\hline & $2011-$ & $\mathrm{E}$ & 666 & $97.7(31.8)$ & -4.3 & $<0.001$ & \multirow[t]{2}{*}{0.21} \\
\hline & $2012(\$ 600-\$ 1200)$ & $\mathrm{C}$ & 641 & $101.7(33.3)$ & -6.2 & $<0.001$ & \\
\hline Weight (kg) & $2008-2009(\$ 100)$ & $\mathrm{E}$ & 467 & $97.8(23.6)$ & -1.2 & $<0.001$ & $<0.01$ \\
\hline & & $\mathrm{C}$ & 467 & $97.9(26.1)$ & -0.1 & 0.87 & \\
\hline & $2009-2010(\$ 300)$ & $\mathrm{E}$ & 613 & $96.6(22.9)$ & -0.7 & $<0.01$ & 0.51 \\
\hline & & $\mathrm{C}$ & 613 & $96.9(23.5)$ & -0.5 & 0.05 & \\
\hline & 2010 & $\mathrm{E}$ & 727 & $96.9(22.8)$ & -0.7 & $<0.01$ & 0.22 \\
\hline & $2011(\$ 600-\$ 1200)$ & $\mathrm{C}$ & 727 & $97.0(23.6)$ & -0.3 & 0.12 & \\
\hline & $2011-$ & $\mathrm{E}$ & 865 & $96.4(23.0)$ & -1.3 & $<0.001$ & 0.25 \\
\hline & $2012(\$ 600-\$ 1200)$ & $\mathrm{C}$ & 865 & $97.2(24.7)$ & -0.9 & $<0.001$ & \\
\hline
\end{tabular}

$E=$ Employee patients, $C=$ non-employee comparison patients, $S D=$ standard deviation

The fact that employees participating in disease management programs had improved $\mathrm{HbA} 1 \mathrm{C}$ and weight compared to nonemployees in the first year of joining supports this interpretation.

Our observation that increasing incentives may have resulted in more patients with better diabetic control joining disease management programs, as evidenced by the lower mean $\mathrm{HbA1c}$ in 2012 compared to 2009, and the finding that disease management program participants had more weight loss than non- participants (Table 4 and Table S9) highlight the difficulty of conducting observational studies of incentives. Without a comparison group, our findings could have been misleading because of selection bias. On a population level, substantial clinical improvements were noted in employees corresponding with the introduction of financial incentives, but almost identical changes were noted in the comparison population. These improvements may be more related to being in care than to incentives tied to specific outcomes once patients are in care.

Employer-sponsored disease management programs are common, ${ }^{14}$ have potential to improve diabetes control ${ }^{20}$ and even prevent diabetes. ${ }^{21,22}$ A successfully designed worksite health promotion model may offer a framework to be utilized in other patient or community populations. Studies of financial incentives have produced mixed results, particularly when incentives target health behaviors. ${ }^{11}$ Randomized trials suggest that financial incentives are effective for improving tobacco cessation rates, ${ }^{10,12}$ compliance with home monitoring for diabetes, ${ }^{23}$ and reducing LDL. ${ }^{24}$ In contrast, incentives were not effective in promoting health behaviors such as walking ${ }^{25}$ or weight loss. ${ }^{26}$ Our study adds to this body of knowledge by reporting the impact of financial incentives tied to treatment targets on measures of disease control.

One goal of financial incentives is to engage patients who otherwise would not have sought care, and this may be the most important effect of offering the incentives. Our longitudinal model suggests an overall benefit of disease management programs, and our pooled analysis of program participants suggest benefit in the first year of joining. However, even with potential rewards of $>\$ 1000$ annually, no more than $50 \%$ of patients agreed to participate. There is scant literature on why patients decline disease management despite incentives. One potential explanation for the lack of association we observed between financial incentives and short-term diabetes outcomes among patients already seeking care is that the incentives were not optimally structured to motivate behavior change. ${ }^{27}$ For example, the timing of the incentives - an insurance premium discount applied in the year after achieving treatment targets - may not be as effective as smaller, more frequent payments closer to when goals are achieved. ${ }^{28} \mathrm{Cov}-$ ering copayment costs for medications ${ }^{7,29,30}$ for program participation and not tied to reaching set treatment targets may 
Table 4 Outcome Changes for Disease Management Program Participants at the First Year of Participation and for the Matched Comparison Group using Pooled Data from All Four Cohorts

\begin{tabular}{|c|c|c|c|c|c|c|c|}
\hline \multirow[t]{2}{*}{ Outcome } & \multirow[t]{2}{*}{$\mathbf{N}$} & \multirow{2}{*}{$\begin{array}{l}\text { Year prior to program } \\
\text { participation }\end{array}$} & \multirow{2}{*}{$\begin{array}{l}\text { First year of program } \\
\text { participation }\end{array}$} & \multicolumn{2}{|l|}{ Change } & \multirow[t]{2}{*}{$\begin{array}{l}\text { DMP-MC } \\
\text { estimate }\end{array}$} & \multirow[t]{2}{*}{$\mathbf{p}$} \\
\hline & & & & $\begin{array}{l}\text { Estimate (first } \\
\text { year-baseline) }\end{array}$ & $\mathbf{p}$ & & \\
\hline $\begin{array}{l}\mathrm{HbA1c} \% \text { disease } \\
\text { management participant }\end{array}$ & 457 & $7.38(1.50)$ & $7.06(1.30)$ & -0.33 & $<0.001$ & -0.19 & 0.04 \\
\hline $\begin{array}{l}\text { HbAlc \% matched } \\
\text { comparison }\end{array}$ & 457 & $7.40(1.93)$ & $7.26(1.69)$ & -0.14 & 0.04 & & \\
\hline $\begin{array}{l}\text { Weight }(\mathrm{kg}) \text { disease man- } \\
\text { agement participant }\end{array}$ & 396 & $101.3(21.6)$ & $99.0(21.1)$ & -2.3 & $<0.001$ & -2.1 & $<0.001$ \\
\hline $\begin{array}{l}\text { Weight }(\mathrm{kg}) \text { matched } \\
\text { comparison }\end{array}$ & 396 & $93.1(20.7)$ & $93.0(20.8)$ & -0.1 & 0.73 & & \\
\hline
\end{tabular}

$D M P=$ Disease management participant

$M C=$ Matched comparison

also be considered as an alternative to a premium discount. However, even these types of incentives may yield only modest improvements in medication adherence ${ }^{31}$ and presumably smaller improvements in clinical outcomes. The use of standardized treatment goals may also have discouraged participation by those far from the goals. Recent recommendations for diabetes care to be patient-centered, ${ }^{15}$ and evidence that tailored behavioral interventions are effective for improving control of diabetes and ${ }^{32}$ hypertension ${ }^{33}$ and for increasing physical activity, support individualized treatment goals ${ }^{34}$ such as a mutually agreed upon HbA1c. In the EHP, weight targets were individualized, which may have facilitated the significant weight reduction we observed among employees with a $\mathrm{BMI}>27$ and contributed to the greater weight reductions among employees over 5 years.

Creative incentive design could increase participation and population level benefits. Redesign should include employees with chronic disease as stakeholders to explore barriers to program participation, ${ }^{35-37}$ and to ensure the program and incentive designs are both equitable ${ }^{38}$ and desirable. Shared incentives for patients and physicians may also guide future programs. ${ }^{39}$

\section{Limitations}

This is a single institution study; thus, our observed outcomes may not be generalizable to other workplaces. Organizational factors may have contributed to improved outcomes in patients with diabetes. ${ }^{40}$ Providers - employees of the same health system - may have been prompted to provide similar care to their employee and non-employee patients as a result of awareness of optimal disease management from the incentive program. During this time period physicians also had ample reminders of the importance of diabetes control, a publicly reported quality measure.

We did not measure employee motivation to receive care for diabetes before and after initiation of financial incentives. If the incentive program increased motivation to improve health during our study period, prompted by an invitation to an employee to join disease management (whether or not they joined), the long-term population health benefit may not have been captured by our analysis of changes in 2-year cohorts and may explain the results of our longitudinal modeling analyses. In addition, the baseline diabetes control was good; thus, introduction of financial incentives had little opportunity to improve HbA1c. We also could not determine whether patients in our comparison group participated in disease management sponsored by their employer or insurer.

\section{CONCLUSIONS}

In this study, financial incentives offered to employees with diabetes encouraged employees to enter disease management, and program participation led to initial improvements in diabetes control and weight. Over 5 years, the program appeared to improve disease control. However improvements in diabetic control, weight, LDL cholesterol, and systolic blood pressure temporally related to individual incentive offerings were similar to non-employees obtaining regular care in the same primary care practices. Studies to identify successful elements and a timeline to expected benefits of workplace financial incentive programs are warranted.

\section{Acknowledgments:}

Dr. Glen Taksler was funded by the Clinical and Translational Science Collaborative of Cleveland (grant KL2TR000440) and the National Center for Advancing Translational Sciences.

Author Contributions: Drs. Anita D. Misra-Hebert, Bo Hu, Glen Taksler, and Michael B. Rothberg had access to all the data in the study and take responsibility for the integrity of the data and the accuracy of the data analysis.

Dr. Bo Hu, Department of Quantitative Health Sciences, Cleveland Clinic, conducted and is responsible for the data analysis.

Drs. Anita D. Misra-Hebert, Bo Hu, Glen Taksler, and Michael B. Rothberg made substantial contributions to the conception and design of the project, interpretation of data for the work, and drafting and critically revising the work for intellectual content, have approved the final version, and agree to be accountable for all aspects of the work.

Dr. Robert Zimmerman made substantial contributions to the interpretation of data for the work, drafting and critically revising the work for intellectual content, has approved the final version, and agrees to be accountable for all aspects of the work. 
Corresponding Author: Anita D. Misra-Hebert, MD, MPH; Center for Value-Based Care Research, Medicine InstituteCleveland Clinic, Cleveland, OH, USA (e-mail: misraa@ccf.org).

\section{Compliance with Ethical Standards}

The authors report no financial disclosures.

These data were presented as an oral presentation at the Society of General Internal Medicine national meeting in Toronto, Canada, on April 24, 2015.

This publication was made possible in part by the Cleveland Clinic Research Program Committee pilot funding grant program, \#2013 1055.

Conflict of Interest: The authors declare that they do not have a conflict of interest.

\section{REFERENCES}

1. Overweight and Obesity. http://www.cdc.gov/obesity/adult/index.html. Accessed January 26, 2016.

2. Peyrot M, McMurry JF, Kruger DF. A biopsychosocial model of glycemic control in diabetes: stress, coping and regimen adherence. J Health Soc Behav. 1999;40(2): 141. doi:10.2307/2676370.

3. Benoit SR, Fleming R, Philis-Tsimikas A, Ji M. Predictors of glycemic control among patients with type 2 diabetes: a longitudinal study. BMC Public Health. 2005;5(1):36. doi:10.1186/1471-2458-5-36.

4. Reduction in the Incidence of Type 2 Diabetes with Lifestyle Intervention or Metformin. N Engl J Med. 2002;346(6):393-403. doi:10.1056/ NEJMoa012512.

5. JAMA Network | JAMA | The State of US Health, 1990-2010: Burden of Diseases, Injuries, and Risk Factors. http://jama.jamanetwork.com/article.aspx?articleID=1710486\&utm_source=Silverchair\%20Information\%20Systems\&utm_medium=email\&utm_campaign=JAMA\%3AOnlineFirst07\%2F10\%2F2013. Accessed January 26, 2016

6. Zhuo X, Zhang P, Kahn HS, Bardenheier BH, Li R, Gregg EW. Change in Medical Spending Attributable to Diabetes: National Data From 1987 to 2011. Diabetes Care. 2015;dc141687. doi:10.2337/dc14-1687.

7. American Diabetes Association. Economic costs of diabetes in the US in 2012. Diabetes Care. 2013;36(4):1033-1046. doi:10.2337/dc12-2625.

8. Racette SB, Deusinger SS, Inman CL, et al. Worksite opportunities for wellness (WOW): effects on cardiovascular disease risk factors after 1 year. Prev Med. 2009;49(2-3):108-114. doi:10.1016/j.ypmed.2009.06.022.

9. Giles EL, Robalino S, McColl E, Sniehotta FF, Adams J. The effectiveness of financial incentives for health behaviour change: systematic review and meta-analysis. PLoS One. 2014;9(3), e90347. doi:10.1371/journal. pone.0090347.

10. Volpp KG, Troxel AB, Pauly Mv, et al. A randomized, controlled trial of financial incentives for smoking cessation. N Engl J Med. 2009;360(7):699709. doi:10.1056/NEJMsa0806819.

11. Sutherland $\mathbf{K}$, Christianson JB, Leatherman S. Impact of targeted financial incentives on personal health behavior a review of the literature. Med Care Res Rev. 2008;65(6 suppl):36S-78S. doi:10.1177/ 1077558708324235.

12. Halpern SD, French B, Small DS, et al. Randomized trial of four financialincentive programs for smoking cessation. N Engl J Med. 2015. doi:10. 1056/NEJMoa1414293.

13. Merrill RM, Hyatt B, Aldana SG, Kinnersley D. Lowering employee health care costs through the healthy lifestyle incentive program. J Public Health Manag Pract. 2011;17(3):225-232. doi:10.1097/PHH.0b013e3181f54128.

14. Mattke S, Liu H, Caloyeras JP, et al. Workplace Wellness Programs Study Final Report. 2013. http://www.rand.org/pubs/research_reports/RR254 html. Accessed February 14, 2015

15. American Diabetes Association. 1. Strategies for improving care. Diabetes Care. 2015;38(Supplement 1):S5-S7. doi:10.2337/dc15-S004.

16. McLaren LA, Guinn TJ, McKay GA. Diabetes control in older people. BMJ. 2013;346:f2625. doi:10.1136/bmj.f2625.

17. Siddiqui MA, Khan MF, Carline TE. Gender differences in living with diabetes mellitus. Mater Socio-Medica. 2013;25(2):140-142. doi:10.5455/ msm.2013.25.140-142.

18. Saydah S, Cowie C, Eberhardt MS, De Rekeneire N, Narayan KMV. Race and ethnic differences in glycemic control among adults with diagnosed diabetes in the United States. Ethn Dis. 2007;17(3):529-535.

19. Multivariate and Propensity Score Matching Software with Automated Balance Optimization: The Matching package for R | Sekhon | Journal of
Statistical Software. http://www.jstatsoft.org/article/view/v042i07. Accessed November 15, 2015

20. Yoder VG, Dixon DL, Barnette DJ, Beardsley JR. Short-term outcomes of an employer-sponsored diabetes management program at an ambulatory care pharmacy clinic. Am J Health Syst Pharm. 2012;69(1):69-73. doi:10. 2146/ajhp110041.

21. Rolando L, Byrne DW, McGown PW, Goetzel RZ, Elasy TA, Yarbrough MI. Health risk factor modification predicts incidence of diabetes in an employee population: results of an 8-year longitudinal cohort study. J Occup Environ Med Am Coll Occup Environ Med. 2013;55(4):410-415. doi:10.1097/JOM.0b013e31827cbaec

22. Aldana SG, Barlow M, Smith R, et al. The diabetes prevention program: a worksite experience. AAOHN J. 2005;53(11):499-505. quiz 506-507.

23. Sen AP, Sewell TB, Riley EB, et al. Financial incentives for home-based health monitoring: a randomized controlled trial. J Gen Intern Med. 2014;29(5):770-777. doi:10.1007/s11606-014-2778-0.

24. Bloch MJ, Armstrong DS, Dettling L, Hardy A, Caterino K, Barrie S. Partners in lowering cholesterol: comparison of a multidisciplinary educational program, monetary incentives, or usual care in the treatment of dyslipidemia identified among employees. J Occup Environ Med Am Coll Occup Environ Med. 2006;48(7):675-681. doi:10.1097/01.jom. $0000205997.18143 .6 \mathrm{c}$

25. Kullgren JT, Harkins KA, Bellamy SL, et al. A mixed-methods randomized controlled trial of financial incentives and peer networks to promote walking among older adults. Health Educ Behav. 2014;41(1 Suppl):43S50S. doi:10.1177/1090198114540464.

26. Patel MS, Asch DA, Troxel AB, et al. Workplace wellness incentives for weight loss-A randomized, controlled trial. J Gen Intern Med. 2015;30(2):45-551. doi:10.1007/s11606-015-3271-0. Toronto, CANADA.

27. Loewenstein G, Asch DA, Volpp KG. Behavioral economics holds potential to deliver better results for patients, insurers, and employers. Health Aff. 2013;32(7):1244-1250. doi:10.1377/hlthaff.2012.1163.

28. Volpp KG, Asch DA, Galvin R, Loewenstein G. Redesigning employee health incentives-lessons from behavioral economics. N Engl J Med. 2011;365(5):388-390. doi:10.1056/NEJMp1105966.

29. Gibson TB, Wang S, Kelly E, et al. A value-based insurance design program at a large company boosted medication adherence for employees with chronic illnesses. Health Aff Proj Hope. 2011;30(1):109-117. doi:10. 1377/hlthaff.2010.0510.

30. Choudhry NK, Avorn J, Glynn RJ, et al. Full coverage for preventive medications after myocardial infarction. N Engl J Med. 2011;365(22):20882097. doi:10.1056/NEJMsa1107913.

31. Duru OK, Turk N, Ettner SL, et al. Adherence to metformin, statins, and ACE/ARBs within the diabetes health plan (DHP). J Gen Intern Med. 2015. doi:10.1007/s11606-015-3284-8.

32. Wolever RQ, Dreusicke M, Fikkan J, et al. Integrative health coaching for patients with type 2 diabetes a randomized clinical trial. Diabetes Educ. 2010;36(4):629-639. doi:10.1177/0145721710371523.

33. Friedberg JP, Rodriguez MA, Watsula ME, et al. Effectiveness of a tailored behavioral intervention to improve hypertension control primary outcomes of a randomized controlled trial. Hypertension. 2015;65(2):440446. doi:10.1161/HYPERTENSIONAHA.114.03483.

34. Bock BC, Marcus BH, Pinto BM, Forsyth LH. Maintenance of physical activity following an individualized motivationally tailored intervention. Ann Behav Med Publ Soc Behav Med. 2001;23(2):79-87.

35. Kim AE, Towers A, Renaud J, et al. Application of the RE-AIM framework to evaluate the impact of a worksite-based financial incentive intervention for smoking cessation. J Occup Environ Med. 2012;54(5):610-614. doi:10. 1097/JOM.0b013e31824b2171.

36. Person AL, Colby SE, Bulova JA, Eubanks JW. Barriers to participation in a worksite wellness program. Nutr Res Pract. 2010;4(2):149-154. doi:10. 4162/nrp.2010.4.2.149.

37. Brna SA, Ruisinger JF, Howard PA, Barnes BJ, Hare SE. Study of nonparticipation in an employee diabetes program. J Am Pharm Assoc. 2012;52(5):e105-e108. doi:10.1331/JAPhA.2012.10089.

38. Horwitz JR, Kelly BD, DiNardo JE. Wellness incentives in the workplace: cost savings through cost shifting to unhealthy workers. Health Aff. 2013;32(3):468-476. doi:10.1377/hlthaff.2012.0683.

39. Asch DA, Troxel AB, Stewart WF, et al. Effect of financial incentives to physicians, patients, or both on lipid levels: a randomized clinical trial. JAMA. 2015;314(18):1926-1935. doi:10.1001/jama.2015.14850.

40. van Doorn-Klomberg AL, Braspenning JCC, Wolters RJ, Bouma M, de Grauw WJC, Wensing $\mathbf{M}$. Organizational determinants of high-quality routine diabetes care. Scand J Prim Health Care. 2014;32(3):124-131. doi:10.3109/02813432.2014.960252. 